\section{P-168 LIVING BETTER, DYING WELL - A COORDINATED APPROACH: A SPOONFUL OF CARE HELPS MANY IN OUR TOWNS}

Duncan Fleming, Bev Behmer. Mountbatten, Isle of Wight, UK

10.1136/bmjspcare-2018-hospiceabs.193

Background The nation has an ageing population and our local demographic is approximately five years ahead of the curve in relation to this. It is projected that our $65+$ populaation will increase by 18000 and the $85+$ population will increase by 6500 by 2039 .

Aims Our new coordination centre will mean we can reach more of our population earlier, preventing inappropriate admissions to the acute setting and enabling a planned approach to care. Our desire is to give the correct dose of care to each person at the right time, meaning our finite resources are used effectively and people are not smothered in a blanket of care and become 'a patient'.

Method The criterion for referral into our coordination centre is the last five years of life. All people referred are assessed and a plan put in place. The plan will range from light touch support, including access to our $24 / 7$ support line, social programme and rapid response service, to CNS involvement. Our vision is that more people will fit in to the criteria of the former, enabling a planned approach, with patient's wishes achieved and stress and anxiety managed.

Results Although the project is still in its infancy we have already seen significant positive outcomes from this new way of working. This includes callers able to talk to an expert no matter when they phone, call backs and checking in with people who might otherwise be missed, a heightened awareness of the number of people that will be requiring our services as we move forward and admission avoidance.

Conclusion Accepting referrals for people in the last five years of life is innovative and bold, a brave new model that we believe is necessary to meet the changing needs of our community. \#therightdose.

\section{P-169 DEVELOPING A NEW INNOVATIVE SERVICE: SUPPORTING WOMEN IN LIVING WELL WITH AND AFTER CANCER}

Katie Taroni, Katherine Hill, Claire Owen. St Giles Hospice, Whittington, Staffordshire

\subsection{6/bmjspcare-2018-hospiceabs.194}

The initiative Living with cancer is challenging in a stretched healthcare system. Research indicates there are unmet needs affecting women with cancer due to the uniqueness of their issues (Cheng, Wong \& Koh, 2016). Over a period of 12 months, St Giles Hospice, in partnership with Breast Friends have developed this new innovative service based on research and feedback. Feedback highlighted a clear need to support women who have had body changing surgery, chemotherapy, radiotherapy and continue with long term medications, which have left them with low self-esteem, self-worth and issues with their sexuality and relationships. The service offers day, evening or weekend appointments over three days.

The goals

- Improve the wellbeing of women living with cancer and the adverse effects of its treatments

- Empower women to take control and self-manage a range of problems impacting on their body image, sexuality and wellbeing
- Re-connecting relationships, enabling them to discuss their concerns relating to how cancer and its treatments may impact upon their relationship.

Why the service is unique and innovative

- Empower women to self-refer - in their own time, leading to self-management

- Time to talk openly about concerns with a nurse in a relaxed, safe, confidential and welcoming environment

- Support via ongoing sessions for not only the woman but her partner and family as required

- Easy access to other specialist services via onward referrals or signposting

- A supportive care service that other healthcare professionals can refer/signpost to.

The future Evaluation will be collated over the next 12 months by measuring the success of the intervention on confidence, motivation, anxieties and general state of mind. Questionnaires pre- and post interventions will be gathered and will enable St Giles Hospice to lead and provide evidence based practice to other healthcare professionals which will benefit further women living with cancer and the adverse effects of its treatment.

\section{P-170 THE EAPC CORE DOMAINS FOR DEMENTIA - BENCHMARKING ADMIRAL NURSING}

Karen Harrison Dening, Caroline Scates. Dementia UK, London, UK

\subsection{6/bmjspcare-2018-hospiceabs.195}

There are over 850000 people living with dementia in the UK, with numbers projected to triple by 2050. Dementia prevalence increases with age, affecting $6 \%$ of those aged 75 79 years and a third of people over the age of 95 (Knapp \& Privette, 2007).

Increasing numbers of people will die with dementia and in 2015 dementia became the commonest cause of death in men and women over the age of 80 years (Office for National Statistics, 2017). Deaths due to dementia will increase to around 220,000 deaths per year by 2040 leading to an increased need for palliative care (Etkind, Bone, Gomes et al., 2017). Identifying when people with dementia are reaching the end of their life can be challenging and some studies have attempted to identify prognostic indicators to guide clinicians to adopt a palliative care approach. However, these tools are more reliable at identifying people with dementia at low risk of dying rather than those at higher risk of death (van der Steen, Ooms, van der Wal et al., 2005). So what does palliative care for people with dementia look like'?

Definitions of palliative care share a common philosophy, which is an holistic approach, valuing autonomy of patients and families, focussing on dignity, collaborative relationships between healthcare professionals, patients and their families, good communication, and a central goal to maintain quality of life. The European Association for Palliative Care (EAPC) surveyed experts in the field using a Delphi process and published a consensus statement defining the principles of practice for palliative care in dementia (van der Steen, Radbruch, Hertogh et al., 2014). Around this time Dementia UK developed its 'hospice model' of Admiral Nursing, of which services are growing. This paper will describe benchmarking of the 